\title{
Transition Assessment of the Bangladeshi Financial Market Stress Regimes: A Markov Switching Modeling Approach
}

\author{
Maria Afreen ${ }^{1}$ \\ ${ }^{1} \mathrm{PhD}$ (Financial Economics), Faculty of Economics and Business, University Malaysia Sarawak, Malaysia.
}

\begin{abstract}
Keywords:

Markov Switching

Model, Financial

Regimes, Economic

Distress, Transition

Phases, Bangladesh.

Purpose of study: In view of the global financial crises and the ensuing consequences, this research presents the utility of demonstrating an assessment that can forecast the Bangladeshi financial market's well-being by analysing episodes of economic crises which may prevent market distress. By graphically demonstrating eventual economic episodes in the financial sector, this study sets out to illustrate the chronological scenario of economic turning points. The scope of this research is to study the vulnerable aspects of financial instability in Bangladesh and seek possible remedies.
\end{abstract}

Methodology: The Bangladeshi financial market regimes will be constructed based on Hamilton's Markov Switching Model (1989). This paper is the first attempt in utilising a standardised methodology found in business cycle literatures so as to determine the turning points of economic episodes in the Bangladeshi financial dynamic cycle.

Main Findings: This study examines the financial crises and economic distress experienced by banks as forms of economic vulnerabilities. Thus, it describes the financial regimes of transition period movements in the context of the vulnerability of the Bangladeshi financial market sector using the Markov Switching Modeling (MSM) Approach and shows ways to possibly achieve recovery.

Research Limitations/Implications: This research focuses on the current financial episodes of the economic sector's dynamic movements in a condensed area, while the selection of a broad financial arena of parameters results in more significant and robust outcomes.

Received Date:

14-01-2021

Accepted Date:

08-03-2021

Publication Date:

30-03-2021
Novelty/Originality: Further studies are needed to define and measure the financial cycle concept and its relationship with business cycles, as well as to delineate dynamic models that can offer substantial probabilistic assessments regarding changes in financial cycle regimes. This can significantly develop the capability of the financial market supervisory authorities to forecast macro-prudential systemic risks and to avoid or reduce the consequences of economic crises. This current study provides a platform for future studies in similar fields.

\section{INTRODUCTION}

According to the Hamilton's (1989) Markov Switching Models (MSM) has gained tremendous attention in business cycle literatures for its ability to determine the turning points as well as to specifically indicate recessions. In the case of Bangladesh, the central bank has been involved in containing financial crises and maintaining financial stability whilst preventing liquidity crises. Therefore, amendments to the chronology of the central bank's regulatory authority framework are needed. In Bangladesh, financial institutions like banks face economic shocks caused by several financial downturn attributes or negative economic phases leading to bankruptcy and stock market downfall. This study examines the financial crises and economic distresses faced by banks as forms of economic vulnerabilities. Thus, it describes the financial regimes of transition period movements in the context of the vulnerability of the Bangladeshi financial market sector using the Markov Switching Modeling (MSM) Approach for the period of 1998 to 2015. This research also shows the remedies that should be undertaken by the Government and policymakers to overcome the crises moments in the country's economic distress perspective during the contingency periods.

The real economy was significantly affected by the global financial crisis. Unsurprisingly, policymakers are now focusing on developing models that can produce early warning signals that would trigger the implementation of policies that can improve the resiliency of financial institutions and lessen major risks and costs related to the occurrence of a financial crisis. The Markov switching model (MSM) has been developed to identify business cycle turning points, and subsequently to comprehend the assessments of the Bangladeshi currency, banking and financial crises.

\section{LITERATURE REVIEW}

The credit-to-GDP gap was found to have no significant contribution to the likelihood of going into a financial stress regime during the out-of-sample period consistent with the indication made by Gadea-Rivas and Perez-Quiros (2015). Another similar study is that of Abiad (2007) which assessed the signalling capability of the MS models during the Asian crises and compared it to the outcomes of the standard binary early predicting warning models. Schularick and Taylor (2012) predicted the power of the MSM approaches in exacting statistical measures. This current study however aims to examine the low and high periods

\footnotetext{
${ }^{1}$ Corresponding Author: scholar.maria.afreen@gmail.com
} 
of the financial market regime. Likewise, Gadea-Rivas and Perez-Quiros (2015) examined the function of credit in forecasting major recessionary episodes by assessesing the effect of credit on a business cycle's dynamic turning points. In the current study, we examine several key forecasting indicators in predicting the entry into and exit from chronological episodes of financial market regime of stress.

Different MS models had been employed in analyzing currency crises, but only a small number had focused on banking crises. To demonstrate, Engel and Hakkio (1996) and Martinez-Peria (2002) investigated the European Monetary System currency crisis; Cerra and Saxena (2002), Arias and Erlandsson (2004) and Brunetti et al. (2007) focused on the South-East Asian currency crisis; (Simorangkir, 2012) examined bank runs during the 1997-98 Asian banking crisis; Hollo et al. (2012) concentrated on the European systemic economic and financial stress, whilst Duprey et al. (2015) studied the financial market turmoil in EU countries. Using the MS-VAR model, Hartmann et al. (2013) demonstrated that major output responses to financial stress are far greater with more negative collapse when regime switches are allowed. However, none of the studies had examined the determinants of key switching behaviours. Filardo (1994) and Diebold et al. (1994) proved the existence of time-varying movements in the Markov process which render the likelihood of transitions to be significantly dependent upon a set of key indicators that can effectively forecast the characteristics of the cyclical dynamic fluctuations. Maria Afreen (2020) demonstrated in her research the forecasting of financial distress of country economy perspective related to banking volatility using early warning systems through filtering tools. Thibaut and Benjamin (2017) and Romer and Romer (2015) predicted financial market stress based on the MS model to create a predictive indicator to recover from vulnerability.

\section{METHODOLOGY}

The Markov Switching Model (MSM) or the regime-switching model introduced by Hamilton (1989) is one of the foremost nonlinear models with regards to time series. Multiple structures (equations) are involved in this model in different regimes which are consistent with the time series behaviour. The MSM model is capable of capturing complicated dynamic patterns by permitting switching. The MSM switching mechanism follows a novel feature i.e. the first-order Markov chain which is regulated by an unobservable state variable (Kuan, 2002). In particular, a Markovian structure comprising the property that regulates it depends on its immediate position or past value. It corresponds to the current value which consists of the state variable. Hence, a certain structure may take over for an unknown duration when switching takes place and it would be replaced by another structure.

This is in sharp contrast and is independent over time with the random switching model proposed by Goldfeld and Quandt (1972). The MSM also differs whereby it prevails over the switching events from the models of structural changes. While at random time points, the former allows for frequent changes and the latter admits only exogenous variables with occasional changes. When describing the correlated data, the MSM is suitable for different time periods. This exhibits a distinct dynamic pattern.

Assuming that the value is one or zero, let $s_{t}$ indicate an unobservable means of the state variable for the variable $z_{t}$, a simple switching model involves two auto-regressive (AR) specifications:

$$
z_{t}=\left\{\begin{array}{lr}
\alpha_{0}+\beta z_{t-1}+\varepsilon_{t}, & s_{t}=0 \\
\alpha_{0}+\alpha_{1}+\beta z_{t-1}+\varepsilon_{t}, & s_{t}=0
\end{array}\right.
$$

Where $|\beta|<1$ and $\varepsilon_{t}$ are random variables with mean zero as well as variance $\sigma_{\varepsilon}^{2}$. This is a stationary $\operatorname{AR}(1)$ process with the value of mean $\alpha_{1} /(1-\beta)$ when $s_{t}=0$ and it switches to another stationary $\operatorname{AR}(1)$ process with possessing mean $\left(\alpha_{0}+\alpha_{1}\right) /(1-$ $\beta$ ), when $s_{t}$ changes from 0 to 1 . Then provided that $\alpha_{1} \neq 0$, this model admits at different levels two dynamic structures with regard to the state variable $s_{t}$, depending on the value. In this case, $z_{t}$ are governed by distinct means by two distributions and $s_{t}$ identifies the switching between those two distributions or regimes (Augustyniak, 2014).

In this study, an MSM was developed where the latent specific variable in a sovereign economy can control the sequencial shift regime of periods which were endogenously determined. The model in this specific form could be declared as a little parsimonious. This means that the tests for the endogenous switching could be considered as a simple parameter measuring restriction. Turner, Startz and Nelson (1989) explained that these parameters of the distinguished model are obtained as a measure that can be estimated through the maximum likelihood function with a relatively less and minor modification of the recursive processing of filter. The Monte Carlo experiments with regards to the presence of a process suggested the maximum measurement of likelihood estimation for the endogenous switching models and tested the ratio of the chances with a view to achieve endogeneity which was performed considerably well enough for the process.

In this research, the transitional phases of the Bangladeshi economy's financial episode turning points are shown in a graphical figure based on a couple of variables related to the banking and financial sector's volatility and profitability measuring indicator criteria. The dependent variable selected is return on equity (RoE). Similar research options were obtained by previous authors (Maria, 2020) via the construction of indicators to forecast financial distress by early prediction of volatility measurement. By obtaining these variables options, the transitional turning point movements of financial episodes from the Bangladeshi economic vulnerability perspective are constructed as shown in Figure 1, which is the outcome of this study. This can help policymakers in predicting any future economic shocks by the mesurement of financial market stress phases or eventual regimes. 


\section{RESULTS / ANALYSIS OF THE MARKOV MODEL}

Based on the notion that linearity cannot capture the asymmetric features of existing financial market cycle fluctuations, the MSM for financial market cycle fluctuations is an appealing framework for addressing a particular form of non-linear dynamics that are inherent in most contemporary financial market cycle developments. In this case, Hamilton's (1989) regimeswitching model was first developed to allow the mean of the output growth to evolve according to the two-state Markov Switching process. Therefore, the dynamics of expansion can be quantified differently from those of contraction and render the turning point detection to moderately reflect the stylised facts of the modern financial market cycle. Such similar options of research were undertaken by authors in previous studies (Maria, 2020) to predict vulnerabilty as crises determinants.

The existence of the distinguighed model's significant specification of noteworthy equation comprises the two states of the MSM in modelling with a major single regressor, which entails switching $\mathrm{C}$ and additionally four non-AR switching requirements. By the error considering variance, it is assumed to be common throughout the whole regime. The regressor constant named as $\mathrm{C}$ is probably the only one worth mentioning due to the time-invariant eventual regime significant transition probability.

Based on the empirical findings (Table 1) as suggested by the MSM-AR(4) model, the transition probability of recession in the perspective of the financial episodes of the AR(4) model was found to be overall statistically significant. The model implies the initial aim to characterise the financial market cycle fluctuations into regimes so as to observe the likelihood of regime switching across the investigated time period of 1998 to 2015. In this sense, the MSM-AR(4) model was deemed to be moderately appropriate to illuminate the Bangladeshi financial market cycle. Given that the recession phase is shorter than the expansion phase, the recessionary phases are hence, on average, steeper and shorter than the expansionary phases. This finding is moderately consistent with the Bangladeshi financial market scenario. According to the historical financial market cycle profile of Bangladesh, the duration of the recessionary periods has been moderately longer than that of the expansionary phases. Furthermore, as the log-likelihood ratio statistics from the model have a considerable value, they confirm that the MSM-AR(4) model is accepted in a moderate manner.

Figure also 1 depicts the smoothed probability of recession derived from the MSM-AR(4) model. The smoothed recession probability revealed that past Bangladeshi financial market cycles or macro-prudential cycles had four notable recessionary episodes that were predicted to happen in 2002M10, 2007M03, 2010M08 and 2012M08 and the resulting troughs were marked at 2002M10, 2007M12 and 2010M06 and 2012M12, respectively. These predicted recessionary phases corresponded well with the historical financial market cycle chronology of Bangladesh. The results of the turning point analysis showed that the MS model marked eight major turning points that corresponded to two significant episodes (peak and trough) in the Bangladeshi financial market cycle.

Table 1

Parameter Estimates of Hamilton's (1989) Markov-Switching Model

\begin{tabular}{|c|c|c|c|c|}
\hline Variable & Coefficient & Std. Error & z-Statistics & Prob. \\
\hline \multicolumn{5}{|c|}{ Regime 1} \\
\hline $\mathbf{C}$ & -25.94 & 117.49 & -.2208 & 0.8252 \\
\hline LOG(SIGMA) & 1.307 & 0.061 & 10.89 & 0.0000 \\
\hline \multicolumn{5}{|c|}{ Regime 2} \\
\hline $\mathbf{C}$ & -0.25 .91 & 2138.32 & -0.22 & 0.825 \\
\hline LOG(SIGMA) & -2.66 & 0.0691 & -43.39 & 0.0000 \\
\hline \multicolumn{5}{|c|}{ Common } \\
\hline $\mathbf{A R}(\mathbf{1})$ & 2.21 & 0.0857 & 25.85 & 0.0000 \\
\hline $\mathbf{A R}(2)$ & -0.814 & 0.2523 & -3.22 & 0.0012 \\
\hline $\mathbf{A R}(3)$ & -1.088 & 0.2519 & -4.32 & 0.0000 \\
\hline $\mathbf{A R}(4)$ & 0.687 & 0.0854 & 8.04 & 0.0000 \\
\hline \multicolumn{5}{|c|}{ Transition Matrix Parameters } \\
\hline P11-C & 1.17 & 0.65 & 1.79 & 0.073 \\
\hline P21-C & -3.55 & 0.52 & -6.85 & 0.00 \\
\hline
\end{tabular}

Log Likelihood: 142.56 
Filtered Regime Probabilities

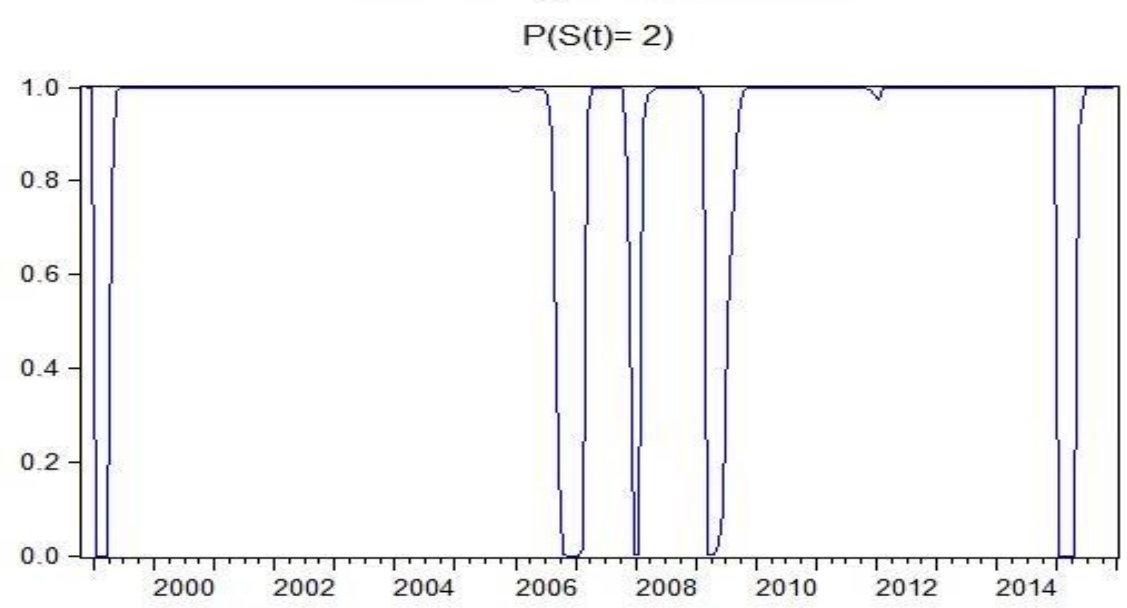

Figure 1: Smoothed Probability of Financial Episodes (1998-2015) for the Bangladeshi Banking Economy.

Although the MSM-AR(4) model illustrated a reasonably moderate general picture regarding the financial market cycle fluctuations of Bangladesh, the univariate MSM-AR(4) model suggested a comparatively short duration of recession in comparison to the real Bangladeshi financial market cycle. Therefore, the drawback of the univariate MSM framework is that it only captures the information content to characterise the broad-based fluctuations of the general macroeconomic activity of a country. This finding explicitly supports the view that the conventional Hamilton's univariate MSM framework tends to be less competent in financial market cycle analysis with monthly observations.

\section{DISCUSSION}

The non-performing loan and minimum capital asset ratio variables signal a transition towards a high regime of financial stress, whilst the prudential parameter of indicators signals a transition towards a more tranquil state in the macro-economy. The in-sample assessment indicates the ability of the indicators in providing early warning signals up to several quarters of a time duration before the stress regime changes; the out-of-sample results demonstrate that the performance is generally determined by the data collected throughout the global economic and financial crises. Maria Afreen (2020) used dynamic tools to describe financial crises in the economic sector. The MS model improves traditional early-warning models by determining an appropriate set of key indicators and detecting significant episodes of chronological financial stress. Further study was carried out on the degree to which this MS framework can add value to its predictive performance in comparison to traditional early-warning models. It was found that the MSM model significantly outperforms most of the model specifications related to the economic episodes of the Bangladeshi financial market sector in terms of financial stress assessment for the country's transition period.

\section{CONCLUDING REMARKS}

In a nutshell, the MS model has outperforming power by constructing an early-warning model that is superior in most specifications to demonstrate the eventual economic episodes to the onset of financial stress of country economy as a whole. The findings also indicate that the early-warning indicators in the MS model's transition function can statistically demonstrate the financial turning points of eventual episodes, which will improve the prediction power with regards to the policymakers to undertake this measure to forecast any possible economic shocks and thus take precautions to overcome contingency volatile sovereign financial distress. This has been portrayed in the transition function of the graphical figure in this research.

\section{LIMITATIONS AND FUTURE RECOMMENDATIONS}

The limitations of a discrete choice model can be identified by using a Markov switching model specifically the time-varying transition probabilities (MS) entailing a greater multifarious estimation process. This model is based on the work of Hamilton (1989) which distinguishes various economic states by examining the incessant dependent variable which identifies the extent of the crises. The model makes no assumptions of the timing of the crises episodes; rather, it deduces the chronological probability of an exact state and the probability of the episode switches. The various eventual regime transitions can be substantially modelled as a hidden Markov chain. The transition matrix permits discerned assessments of the dynamic momentum in entering and exiting the crisis regime. Hence, the MS model enables a non-symmetric analysis of the financial cycle dynamic turning points. Conventional early-warning model systems would have dessimiate less consistent outcome of results preceding to the global financial crisis.

Markov switching (MS) models are found expansively in past business cycle literatures on the identification of turning point dynamics and date recessions. Owing to the unavailability of appropriate incessant measures, filtered types of regime smoothed probabilities demonstrating the financial economic eventual chronological episodes in the Bangladeshi financial sector were employed in literatures on currency, banking and financial volatility to understand the key drivers to the crises 
moments. Policymakers can employ such methodologies to capture the early warning signals so as to improve the resiliency of financial institutions and reduce risks and costs associated with the financial crises.

\section{REFERENCE}

Abiad, A. (2007): "Early Warning Systems for Currency Crises: A Regime-Switching Approach," in Hidden Markov Models in Finance, ed. by R. S. Mamon and R. Elliott, New York: Springer, chap. 10, 155-185.

Arias, G. and U. Erlandsson (2004): "Regime switching as an alternative early warning system of currency crises - an application to south-east asia," Lund University Working Paper.

Afreen, M. (2020). Review Paper on Composite Leading Index Creation for Forecasting the Bangladeshi Financial Sector. International Journal of Finance \& Banking Studies, 9(4), 23-32.

Augustyniak, M. (2014). Maximum likelihood estimation of the Markov-switching GARCH model. Computational Statistics \& Data Analysis, Elsevier, 76(2), 61-75.

Brunetti, C., R. S. Mariano, C. Scotti, and A. H. Tan (2007): "Markov switching garch models of currency turmoil in southeast asia," Federal Reserve Board, International Finance Discussion Papers No. 889.

Cerra, V. and S. C. Saxena (2002): "Contagion, monsoons, and domestic turmoil in Indonesia's currency crisis," Review of International Economics, 10, 36-44.

Diebold, F. X., J.-H. Lee, and G. C. Weinbach (1994): "Regime switching with time-varying transition probabilities," in Nonstationary Time Series Analysis and Cointegration, ed. by C. Hargreaves, Oxford University Press, 283-302.

Duprey, T., B. Klaus, and T. A. Peltonen (2015): "Dating systemic financial stress episodes in the EU countries," ECB Working Paper No. 1873.

Engel, C. and C. S. Hakkio (1996): "The distribution of exchange rates in the EMS," International Journal of Finance and Economics, 1, 55-67.

Filardo, A. (1994): "Business-cycle phases and their transitional dynamics," Journal of Business and Economic Statistics, 12, 299-308.

Gadea-Rivas, M. D. and G. Perez-Quiros (2015): "The failure to predict the great recession - A view through the role of credit," Journal of the European Economic Association, 13, 534-559.

Goldfeld, S., \& Quandt, R. (1972). Nonlinear methods in econometrics. Amsterdam: North-Holland Publ. Co., Amsterdam and London.

Hamilton, J. D. (1989). A new approach to the economic analysis of non-stationary time series and the business cycle. Econometrica, 57(2), 357-384.

Hartmann, P., K. Hubrich, M. Kremer, and R. J. Tetlow (2013): "Melting down: Systemic financial instability and the macroeconomy," Working Paper.

Hollo, D., M. Kremer, and M. Lo Duca (2012): "CISS - a composite indicator of systemic stress in the financial system," ECB Working Paper No. 1426.

Kuan, C. M. (2002). Lecture on Markov Switching Model. Institute of Economics, Academia Sinica, 8(15), 1-30.

Maria, A. (2020) " Construction of an Industry Cycle Indicator for Profitability Prediction Analysis of Aggregate Firms in Bangladesh. International Journal of Social Sciences and Economic Review. 2(4), 9-18.

Martinez-Peria, M. S. (2002). "A regime-switching approach to the study of speculative attacks: A focus on EMS crises," Empirical Economics, 27, 299-334.

Maria, A. (2020). Analysing the Return on Asset to Construct Foretelling Indicator for Bangladeshi Banking Sector. International Journal of Finance \& Banking Studies. 9(4), 11-22.

Maria, A. (2020). Building Vulnerability Predictive Indicator for the Banking Sector: Perspective of Bangladesh. International Journal of Finance \& Banking Studies. 9(3), 01-14.

Romer, C. D. and Romer. D. H. (2015). "New evidence on the impact of financial crises in advanced countries," NBER Working Paper No. 21021.

Schularick, M. H. and Taylor, A. M. (2012). "Credit Booms Gone Bust: Monetary Policy, Leverage Cycles, and Financial Crises, 1870-2008," American Economic Review, 102, 1029-1061.

Simorangkir, I. (2012). "Early warning indicators study of bank runs in Indonesia : Markov-switching approach," Bulletin of Monetary Economics and Banking, 15, 3-39.

Turner, M., Startz, H., \& Nelson, R. (1989). A Markov Model of heteroskedasticity, risk, and learning in the stock market. Journal of Financial Economics, 25(1989), 3-22.

Thibaut, D. \& Benjamin, K. (2017). How to predict financial stress? An assessment of Markov switching models. European Central Bank. ECB Working Paper Series. No: 2057.

\section{Author's Biodata:}

Maria Afreen: Dr. Maria Afreen Completed her Ph.D. in "Financial Economics" from University Malaysia Sarawak, Malaysia in 2018 with a merit-based scholarship. She has expertise in data analysis in the areas of Volatility Forecasting \& Macro-economic Modeling, Credit Risk Management, Constructing Risk Indicator \& Filtering tools. She has a remarkable number of high impact factor indexed peer-reviewed journal publication records at the international level. 